\title{
El Sello del Espíritu Derramado Sobre la Carne. Retórica de la presencia, mediaciones rituales y enacción del Espíritu Santo en el culto pentecostal ${ }^{*}$
}

\author{
Rodrigo Moulian Tesmer
}

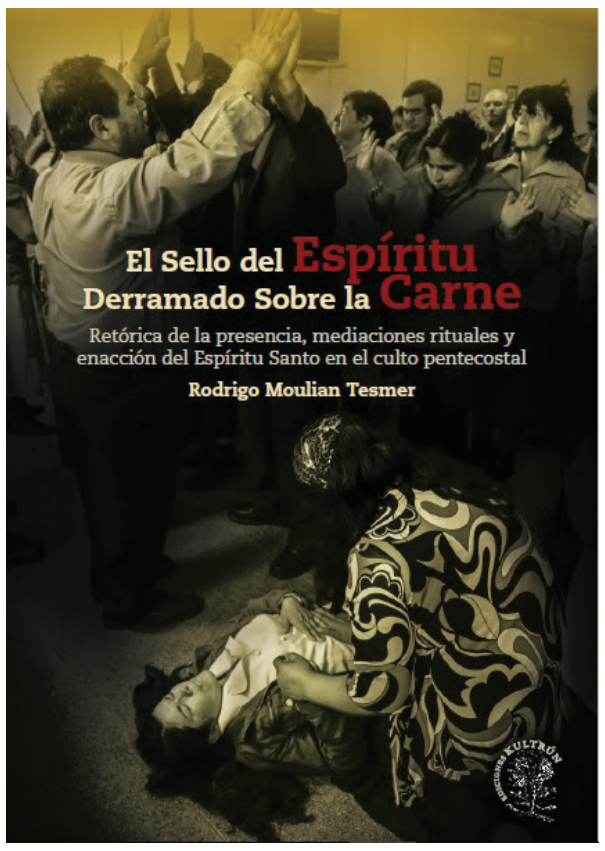

Manuel Antonio Baeza R.

En su libro El sello del Espíritu derramado sobre la Carne (2018), el antropólogo Rodrigo Moulian expone de manera novedosa aquello 
que hace del pentecostalismo una religión para la cual la corporalidad la distingue de otras formas religiosas presentes en América Latina. Para analizar esta contribución antropológica vale la pena comenzar restableciendo el valor de la espontaneidad y la experiencia directa de relación con la esfera de lo divino que caracterizaba al cristianismo primitivo y que la posterior intelectualización de la fe y con ella la especialización-dicho esto último en términos de Weber-que acompañó la pretensión de tenencia de exclusividad en materia de técnicas salvíficas por parte de instituciones eclesiásticas terminó diluyendo de manera drástica.

Ahora bien, con el pentecostalismo Moulian nos plantea, más allá de tal pérdida ya antigua, su importante recuperación, especialmente en medios populares, considerando así que la espontaneidad y la expresión corporal, en sentido fenomenológico, constituyen una respuesta a "lo racionalizado" en exceso:

(...) la clave del éxito del pentecostalismo se encuentra en el tipo de experiencia que suscita. La suya es una religiosidad somatizada: emotiva, sintomática, extática, vivida en carne propia, biográficamente anclada (Moulián 2017: 38).

Ésta es una línea argumentativa sin duda original. Como es sabido, el mundo evangélico pentecostal nacional ha sido tratado por numerosos autores (Willems 1967; Lalive d'Epinay 1968; Tennekes 1985; Lagos y Chacón 1987; Fediakova 2013; Orellana 2006, entre otros) al igual que a escala latinoamericana (Parker 1993; Bastian 1994; Campos 1997; Chiquete y Orellana 2008), pero en todos estos textos el énfasis fue puesto, la mayor parte de las veces, en factores históricos, sociales y hasta políticos, no necesariamente en lo propiamente vivencial. El autor incursiona, por el contrario, en la somatosemiosis -o somatognosis-, o sea en aquello que tiene que ver con una actitud favorable al aprendizaje de lo divino, de lo numinoso de acuerdo a Otto, a través de la experiencia sensible del cuerpo. Es entonces una vivencia enteógen; o si se prefiere, una vivencia de tipo hierofánico en palabras de Eliade, realizada por y en el creyente de manera psicosomática.

Por cierto, no es menor el tema de la homologación de múltiples y diversas manifestaciones espontáneas, tales como la emoción y el Ilanto, el habla en lenguas desconocidas, lo que implica tanto el rol de la comunidad de fieles como la tarea del pastor desde una perspectiva de disciplinamiento y de "normalización" relativa de esas expresiones registradas en el templo, tal como lo muestra esta intervención -captada 
por Moulian- de un corista invitado amonestando a los asistentes, por aquello que le parece ser precisamente un problema de homologación:

He visto aquí danzas mundanas, emociones humanas y falsos profetas, porque cuando habla el profeta mayor, que es la Biblia, todos callan, ningún profeta se levanta para interrumpir la palabra del Señor. No es lícito que los pastores se dejen ungir por falsos instrumentos. Los recién nacidos en Cristo están atemorizados por las manifestaciones. El Espíritu Santo no es así, es suave, tierno, cuidadoso. Lo que aquí se ha manifestado es un espíritu de error, de confusión. Por eso conmino a los pastores a que se humillen ante Dios y le pidan perdón. De lo contrario, Dios los castigará (Moulian 2017: 41).

Se ha nombrado la Biblia, y ésta es esencialmente mensaje por medio de la palabra. Pero de inmediato ha de decirse que con esta última se encuentra presente también un enorme desafío, que debe ser resuelto por ese mismo mensaje de un alcance tanto universal (es decir, para todos los seres humanos esparcidos en este mundo) como atemporal (para todas las épocas históricas) y para lo cual la metonimia, la parábola discursiva, son recursos necesarios en el texto. La lectura de la Biblia es entonces una temática mayor. En la cuestión de tal lectura, la forma religiosa predominante que observamos aquí será la perspectiva filológica clásica, según nosotros, por sobre la hermenéutica teológica, lo que introduce una clara diferencia con el tratamiento bíblico realizado por el catolicismo.

La eficacia simbólica de la retórica es, en síntesis, un elemento notable, la dinámica de la rogativa en el espacio del culto, en la escenificación del templo. La presencia del Espíritu Santo es ofrecimiento divino de inteligibilidad, como en el ejemplo de Babel, lo cual inspira la inclinación del creyente hacia la recepción de ese componente trinitario; en el campo evangélico pentecostal se realiza en sintonía con tan magno acontecimiento el llamado avivamiento espiritual, fenómeno de apertura consciente hacia el carisma que se desarrolla directamente con la retórica, con "la palabra eficaz". Pero sin duda hay más. Moulian nos conduce a la distinción entre soma y sema, para ampliar la mirada hacia el lenguaje corporal -somatolalia- a la vez que hacia el acto ilocutivo -la intencionalidad del hablante- con lo cual se profundiza e intensifica este tipo de vivencias. Es la semántica que se precisa para comprender lo que la corporalidad somatiza, lo que vive y dice lo que vive.

Es en el culto que se lleva a cabo una "mediación psicosocial", una catarsis grupal, lo que implica un alto valor de lo comunitario en un ritual que, siendo extenso, pone en escena todo un habitus carismático 
pentecostal, que otorga importancia tanto a una determinada estética personal -como acto destinado a agradar a Dios- como a una ética virtuosa que es lo propio y lo adecuado para conducir una "nueva vida". Por otra parte, la música tiene también un lugar central, con himnos de confirmación, de esperanza, de guerra, de victoria:

(...) es posible ver a los hermanos y hermanas entregados al canto con todo su cuerpo, con un compromiso ventroabdominal, laríngeo y bucal, que da volumen y modula la voz, y se acompaña de una fuerte actividad kinésica (Moulian 2018: 97).

Resulta interesante penetrar aún más, acompañando a Moulian, en la relación entre cuerpo y fe. En un primer sentido pneumatológico, la fe puede ser vista a través de una revelación de lo divino, vale decir algo que se encuentra "fuera" del cuerpo del creyente; a propósito de esta idea de lo externo podríamos simplemente recurrir, a modo de ejemplo - esta vez en el catolicismo- a la experiencia de Bernadette Soubirous y la conocida aparición mariana en Lourdes, experiencia que, para realizarse de un modo u otro, requiere la intromisión de la razón. Sin embargo, en un segundo sentido, con el pentecostalismo nos encontramos con una manifestación "dentro" del cuerpo de un creyente que necesita sentir -no racionalizar- lo divino, encarnado en él. El advenimiento del Espíritu Santo en el cuerpo, en la lógica somatognóstica, es ni nada menos que la transformación del cuerpo en un receptáculo de lo divino, la gracia, los dones (véase don de la palabra, glosolalia o xenoglosia y también don de la sanidad). Es una auténtica poiética de la encarnación, lo que el autor ha llamado antes "la retórica de la presencia" (Moulian 2007) o, dicho en el lenguaje de Varela y al que también recurre Moulian, el principio de enacción evidenciado en el Espíritu Santo. Hay aquí un cambio de episteme, un desafío a la razón moderna, más exactamente a la razón instrumental.

La sumisión al Dios que se invoca enuncia la presencia de un ser todopoderoso, frente al cual toda la dificultad propia de la vida terrenal es presentada: la enfermedad, el alcoholismo, pero también la falta de trabajo, la soledad, etc. En este sentido, la idea de "dentro" del cuerpo se pone en evidencia. Si Satán es el responsable de la enfermedad, es porque el cuerpo puede estar habitado por el bien (la gracia) o por el mal (el estigma); el pastor y la comunidad desplegarán esfuerzos -en cadenas de oración- por "sacar" al Maligno de un cuerpo enfermo y así recuperar la salud.

Sería perfectamente erróneo suponer que este retorno a la espontaneidad en materia religiosa sea un hecho constatable solamente en sectores 
periféricos pobres de la urbe. La expansión del mundo pentecostal se debe básicamente a la superación innegable de los límites socioterritoriales de los comienzos hacia 1900, sobre todo a través de la obra del pastor Hoover. En nuestros días, tal expansión alcanza sectores rurales y también sectores medios ilustrados de la población, con lo cual lo que hoy conocemos como el fenómeno neo-pentecostal se encuentra estructurado en base a un giro epistémico, o si se prefiere, un descentramiento ontológico del ser pentecostal, ahora en una relación más próxima de la realidad mundana. Se preparan así, muy probablemente, con renovadas visiones intramundanas, nuevas efervescencias en el plano de la religión en América Latina. Con ese horizonte, es indudable que el libro de Moulian constituye una contribución importante para la comprensión de un universo religioso que representa, de lejos, el segmento de población protestante más numeroso en nuestro continente.

\section{Bibliografía}

Bastian, J. P. 1994. Le protestantisme en Amérique latine. Une approche socio-historique. Genève: Éditions Labor et Fides.

Campos, B. 1997. De la Reforma protestante a la pentecostalidad de la Iglesia. Debate sobre el pentecostalismo en América Latina. Quito: Ediciones CLAI.

Chiquete, D. y Orellana, L. 2009. Voces del pentecostalismo latinoamericano. Hualpén: Red Latinoamericana de Estudios Pentecostales.

Fediakova, E. 2013. Evangélicos, política y sociedad en Chile: dejando "el refugio de las masas" 1990-2010. Santiago: CEEP / IDEA.

Lagos, H. y Chacón, A. 1987. Los evangélicos en Chile: una lectura sociológica. Concepción: LAR \& Presor.

Lalive d'Epinay, Ch.1968. El refugio de las masas. Estudio sociológico del protestantismo chileno. Santiago: Editorial del Pacífico.

Moulián, R. 2007. "Retórica de la presencia en el culto pentecostal: desde la necesidad al disciplinamiento". Revista GHREBH, 10.

Orellana, L. 2008. El fuego y la nieve. Historia del movimiento pentecostal en Chile: 1909-1932. Concepción: CEEP.

Parker, C. 1993. Otra lógica en América Latina: religión popular y modernización capitalista. Santiago: Fondo de Cultura Económica.

Tennekes, H. 1985. El movimiento pentecostal en la sociedad chilena. Iquique: CIREN.

Willems, E. 1967. Followers of the New Faith: Culture and Rise of Pentecostalism in Brazil and Chile. Nashville: Vanderbilt University Press. 
